\title{
O DIREITO FUNDAMENTAL À LIBERDADE DE CONSCIÊNCIA E À IGUALDADE A PARTIR DO CASO "MASTERPIECE CAKESHOP V. COMISSÃO DE DIREITOS CIVIS DO COLORADO"
}

Thiago Penido Martins ${ }^{1}$ Stéphanie Nathanael Lemos ${ }^{2}$

Resumo: Recentemente, a Suprema Corte dos Estados Unidos admitiu recurso referente a caso em que uma confeitaria se negou a confeitar um bolo para um casamento homossexual, alegando objeção de consciência, por razões religiosas, analisará o suposto conflito entre o direito fundamental à liberdade de consciência e à igualdade. Em decorrência da importância histórica do Direito norte-americano no Direito ocidental e da influência por aquele exercida no ordenamento jurídico brasileiro, o desfecho do caso, muito provavelmente, repercutirá no Brasil. Por esse motivo, merece criteriosa análise, à luz do Direito brasileiro, objetivo deste trabalho.

Palavras-chave: Liberdade de consciência; Liberdade religiosa; Direito à igualdade; Discriminação; Direitos Fundamentais.

\section{THE FUNDAMENTAL RIGHT TO FREEDOM OF CONSCIOUSNESS AND EQUALITY FROM THE CASE "MASTERPIECE CAKESHOP V. COLORADO CIVIL RIGHTS COMMISSION"}

\begin{abstract}
The recent admission by the United States Supreme Court of an appeal against a case where a confectionery refused to make a cake for a homosexual marriage, claiming conscientious objection for religious reasons, will analyze the alleged conflict between the fundamental right to Freedom of conscience and equality. Due to the historical importance of US law in Western law and the influence exerted by it in the Brazilian legal system, the outcome of the case will most likely have repercussions in Brazil. For this reason, it deserves careful analysis, in the light of Brazilian Law, the objective of this work.
\end{abstract}

Keywords: Freedom of conscience; Religious freedom; Right to equality; Discrimination.

\footnotetext{
${ }^{1}$ Doutor em Direito pela Pontifícia Universidade Católica de Minas Gerais. Mestre em Direito pela Faculdade de Direito Milton Campos. Especialista em Direito pela Faculdade de Direito Milton Campo.

${ }^{2}$ Mestranda no Programa de pós-graduação Stricto Sensu da Universidade de Itaúna. Pós-graduada em Gestão Pública Municipal pela Universidade Federal de Uberlândia.
} 


\section{Introdução}

Em 26 de junho de 2017, a Suprema Corte dos Estados Unidos comunicou a admissão do recurso referente a um caso emblemático, ocorrido em 2012, no Estado do Colorado. Tratase de caso no qual se discute se um confeiteiro teria o direito de se recusar a confeitar um bolo de casamento para um casal homossexual, alegando motivos de escusa de orientação religiosa. Na ocasião, o proprietário da confeitaria Masterpiece Cakeshop se negou a confeitar um bolo, sob o argumento de que, se o fizesse, estaria agindo contra suas crenças religiosas, violando seu direito de crença e religião.

A relevância do caso decorre do suposto conflito entre os direitos fundamentais à liberdade religiosa e da proibição da discriminação, assentada no direito à igualdade, direitos fundamentais particularmente importantes para os americanos, em razão de sua cultura marcada por fortes traços liberais. Ademais, há que se ressaltar que a questão adquire maior relevância se se considerar que, historicamente, o direito norteamericano exerce profundas influências na construção dos ordenamentos jurídicos de todo o mundo, em especial o brasileiro.

Nesse sentido, o entendimento a ser adotado no caso pela Suprema Corte dos Estados Unidos, provavelmente, irá repercutir no ordenamento jurídico brasileiro, uma vez que, no texto da Constituição da República 1988, liberdade de crença e religião e igualdade são princípios jurídico-constitucionais ${ }^{3}$ que estruturam o Estado Democrático de Direito. Não obstante, o princípio da igualdade constitui objetivo fundamental da República, consagrado no artigo $3^{\circ}$, inciso IV, e a liberdade de consciência, direito fundamental firmando no artigo $5^{\circ}$, caput e incisos VI e VIII ${ }^{4}$.

O julgamento do caso norteamericano certamente reacenderá discussões acerca do conflito entre a liberdade de crença e religião, o direito de igualdade e a proibição de discriminação, bem como a polêmica questão da eficácia dos direitos fundamentais nas relações

\footnotetext{
${ }^{3}$ SILVA, José Afonso da. Curso de Direito Constitucional Positivo. 26a ed. rev. e atual. São Paulo: Ed. Malheiros, p. 92-93, 2005.

${ }^{4}$ Art. $5^{\circ}$. Todos são iguais perante a lei, sem distinção de qualquer natureza, garantindo-se aos brasileiros e aos estrangeiros residentes no País a inviolabilidade do direito à vida, à liberdade, à igualdade, à segurança e à propriedade, nos termos seguintes: VI - é inviolável a liberdade de consciência e de crença, sendo assegurado o livre exercício dos cultos religiosos e garantida, na forma da lei, a proteção aos locais de culto e a suas liturgias; (...) VIII - ninguém será privado de direitos por motivo de crença religiosa ou de convicção filosófica ou política, salvo se as invocar para eximir-se de obrigação legal a todos imposta e recusar-se a cumprir prestação alternativa, fixada em lei (BRASIL, 1988).
} 
jurídicas entre particulares, no caso, a extensão da eficácia do princípio da igualdade nas relações jurídicas privadas face ao direito de liberdade e á autonomia privada. É possível que um particular, alegando se direito de crença e religião, se recuse a contratar com outrem?

Para a análise proposta, é necessário o estudo do caso sob a perspectiva da legislação brasileira, com o desiderato de se responder aos seguintes questionamentos: Qual o conteúdo e alcance do direito de liberdade de crença e religião? O direito à objeção de consciência religiosa permite a que alguém se recuse a contratar com outrem? Qualquer indivíduo pode alegar objeção de consciência por razões religiosas? Qual a extensão da eficácia do princípio da igualdade nas relações entre particulares? A recusa em contratar com fundamento em objeção de consciência religiosa constitui discriminação ilícita?

\section{Masterpiece Cakeshop Vs. Colorado Civil rights Commission}

O caso submetido à Suprema Corte dos Estados Unidos ocorreu em 2012, no Estado do Colorado, quando Jack Philips, proprietário da confeitaria Masterpiece Cakeshop, se negou a confeitar um bolo de casamento para um casal homossexual, David Mullins e Charlie Craig, sob o argumento de que tal conduta iria de encontro às suas crenças religiosas. Diante da recusa de Jack Philips, o casal Charlie Craig e David Mullins registrou denúncia junto à Comissão de Direitos Civis do Colorado, alegando violação às leis antidiscriminatórias daquele Estado, as quais protegem as pessoas em razão de sua orientação sexual ${ }^{5}$.

Na oportunidade, a Comissão de Direitos Civis do Colorado decidiu contra o confeiteiro Jack Phillips, declarando que ele, ao se negar a confeitar, sob encomenda, o bolo para o casamento, cometeu ato discriminatório em razão da orientação sexual do casal. No mesmo sentido, pronunciou-se o Tribunal de Apelações do Colorado ao confirmar a decisão (ADAM LIPTAK, 2017), adotando o entendimento de que a prática foi discriminatória, não estando amparada pelo direito de liberdade de crença e religião do confeiteiro.

\footnotetext{
${ }^{5}$ The New York Times. Justices to Hear Case on Religious Objections to Same-Sex Marriage. New York. 26 jul. 2017. Disponível em: <https://www.nytimes.com/2017/06/26/us/politics/supreme-court-wedding-cake-gaycouple-masterpiece-cakeshop.html?mcubz=0>. Acesso em 23 jul. 2017.
} 
A Suprema Corte norteamericana ao admitir o recurso que pretende a revisão da decisão do Tribunal de Apelações do Colorado, irá analisar o conflito estabelecido entre o direito de liberdade religiosa do confeiteiro e sua autonomia privada, e o direito do casal em não ser discriminado em razão de sua orientação sexual (STEVE KURTZ, 2017), assentado no princípio da igualdade, analisando em que medida os particulares, em suas relações privadas, se encontram vinculados ao princípio da igualdade bem como se seria legitima a recusa em contratar baseada em uma escusa de ordem religiosa.

Noutras palavras, a Suprema Corte norteamericana enfrentará, de um lado, o argumento de Philips, que afirma não ser obrigado a confeitar um bolo para homenagear um casamento entre pessoas do mesmo sexo, por fazer ter o direito à liberdade de expressão e de religião, consagrado na Primeira Emenda da Constituição americana. De outro lado, deverá analisar o argumento de Charlie Craig e David Mullins, que alegam a prática de ato discriminatório, em decorrência de sua orientação sexual, e a consequente violação do direito a igualdade.

\section{Direito Fundamental à Liberdade de Religião e o Direito à Igualdade no ordenamento jurídico brasileiro}

Não restam dúvidas da relevância da análise, pela Suprema Corte dos Estados Unidos, do conflito entre princípios tão caros à sociedade norteamericana. Em razão da influência do direito norte-americano nos demais ordenamentos jurídicos, o caso é de igual relevância para a sociedade brasileira, cujo texto constitucional consagra como objetivo fundamental da República a promoção do bem de todos, sem discriminação, e a garantia do direito fundamental à liberdade, nos artigos nos artigos $3^{\circ}$, inciso IV, e $5^{\circ}$, caput e incisos VI e VII.

Note-se que os direitos fundamentais objeto de análise neste trabalho, estão positivados no artigo $5^{\circ}$ da Constituição da República como princípios constitucionais. Consoante José Afonso da Silva (2015, p. 92-93), os princípios constitucionais podem ser divididos em princípios constitucionais políticos e jurídicos. Quanto aos princípios político-constitucionais, são também conhecidos como princípios fundamentais ou princípios estruturantes do estado constitucional, presentes nos artigos $1^{\circ}$ a $4^{\circ}$ da Constituição da República, por exemplo. Quanto jurídico-constitucionais, destaca serem os princípios constitucionais gerais informadores da ordem jurídica nacional. São emanados das normas constitucionais, acarretando alguns 
desdobramentos, como o princípio da liberdade e o da igualdade (SILVA, 2015, p. 92-93), aqui intitulados apenas direitos fundamentais.

Ressalvadas as peculiaridades jurídicas do ordenamento norte-americano, a fim de se compreender a devida dimensão dos direitos envolvidos, nos tópicos seguintes, cuidar-se-á da análise do direito fundamental à liberdade religiosa e à igualdade, bem como direitos outros direitos fundamentais que com esses se relacionam, tomando-se por referência o ordenamento jurídico brasileiro.

\subsection{Direito Fundamental à Liberdade Religiosa}

A influência da religiosidade na sociedade humana remonta os primórdios da humanidade. Sua presença é perceptível em diversos aspectos, desde em ritos que celebram o nascimento, à influência na construção da moral social, à influência política na história de suas relações institucionais com o Estado e, principalmente, no cotidiano dos particulares (MORAIS, 2011, p. 226).

Para Daniel Sarmento (2007), "a laicidade caracteriza-se como uma verdadeira garantia institucional da liberdade religiosa individual". A posição de laicidade de um Estado não significa a adoção de uma religiosidade ateísta, que nega a existência de um Deus, mas tão somente que o Estado assume uma posição de neutralidade quanto às diferentes concepções religiosas, sendo-lhe vedado favorecimento ou embaraço de qualquer cresça.

Nesse sentido, reforça Sarmento (2007) ser "o ateísmo, na sua negativa da existência de Deus, também uma crença religiosa, que não pode ser privilegiada pelo Estado em detrimento de qualquer outra cosmovisão". O autor também pondera que o princípio do laicidade Estatal pode ser diretamente relacionado a dois outros direitos fundamentais extremamente relevantes: liberdade de religião e igualdade.

Ademais, não se pode olvidar que a liberdade de crença é religião também constitui um dos pilares da autonomia privada e do direito ao livre desenvolvimento da personalidade assegurado a cada indivíduo, a partir do reconhecimento de que cada indivíduo tem o direito de 
autodeterminar-se nos mais variados aspectos de sua personalidade, sejam elas sexuais, religiosos, ideológicos.

No mesmo sentido, Cláudio Márcio Bernardes e Márcio Eduardo Senra Nogueira Pedrosa (2017) afirmam ser o princípio da liberdade religiosa um direito natural positivado no texto constitucional, e, por essa razão, assume condição de direito fundamental que, juntamente com o princípio democrático e o princípio da igualdade, é constituinte do princípio da laicidade estatal.

Priscila Ferreira Nobre Rocha (2010) sintetiza a relação entre os princípios democrático, de igualdade e de laicidade, demostrados acima, nos seguintes termos: "Desse modo, não há, em um estado laico, privilégios concedidos a alguma opção religiosa, pois a laicidade implica na neutralidade do Estado, o qual é fundamento no princípio da igualdade".

A posição de neutralidade não se restringe apenas às relações tomadas entre Estado e os particulares. No caso Masterpiece Cakeshop v. Colorado Civil Rights Commission, por exemplo, o imbróglio se desenvolve entre particulares, ou seja, entre o confeiteiro e o casal de homossexuais, de forma a tornar-se necessária e imprescindível a compreensão das demais liberdades englobadas pela expressão "liberdade religiosa".

Márcio Eduardo Pedrosa Morais (2015, p.79-82) afirma ser a liberdade religiosa gênero, do qual se desdobram as espécies liberdade de consciência, de crença, de culto e de organização. Ingo Wolfgang Sarlet (2015), ao definir a liberdade religiosa como direito subjetivo ${ }^{6}$, afirma que ela se desdobra nas liberdades de consciência, de crença e de culto, sendo as últimas usualmente abrangidas pela expressão genérica "liberdade religiosa". Para o autor:

em uma liberdade de crença, que diz com a faculdade individual de optar por uma religião ou de mudar de religião ou de crença, ao passo que a liberdade de culto, que guarda relação com a exteriorização da crença, diz com os ritos, cerimônias, locais e outros aspectos essenciais ao exercício da liberdade de religião e de crença. Também

\footnotetext{
${ }^{6}$ Quanto à eficácia dos direitos fundamentais que aqui serão verificados, Sarlet (2015) afirma que esses apresentam uma dupla dimensão subjetiva e objetiva. Em termos gerais, na condição de direitos subjetivos, eles asseguram tanto a liberdade de confessar (ou não) uma fé ou ideologia, quanto geram direitos à proteção contra perturbações ou qualquer tipo de coação oriunda do Estado ou de particulares. Na condição de direitos objetivos, tais liberdades fundamentam a neutralidade religiosa e ideológica do Estado.

Destaca com prioridade o autor, que dessa dupla dimensão subjetiva e objetiva decorrem tanto direitos subjetivos, quanto princípios, deveres de proteção e garantias institucionais que guardam relação com a dimensão objetiva. Ressalta que quanto aos direitos subjetivos, esses podem ter como seus titulares tanto pessoas físicas quanto jurídicas. Porém, a pessoa jurídica não faz jus à liberdade de consciência, mas somente à liberdade religiosa e ainda assim, não quanto a todos os seus aspectos (SARLET, 2015).
} 
a liberdade de associação e de organização religiosa encontra-se incluída no âmbito de proteção da liberdade religiosa, de tal sorte que ao Estado é vedado, em princípio, interferir na esfera interna das associações religiosas.

Consoante os ensinamentos de Silva (2015, p. 249), a liberdade de crença se aproxima mais da liberdade de escolha de aderir ou não a determinada religião, não compreendendo a "liberdade de embaraçar o livre exercício de qualquer religião, de qualquer crença, pois aqui também a liberdade de alguém vai até onde não prejudique a liberdade de outro". No tocante à liberdade de culto, Silva, ao endossar o entendimento de Ponte de Miranda, afirma compreender na liberdade de culto a de orar e praticar os atos próprios das manifestações exteriores em casa ou em público.

Já a liberdade de organização religiosa permite que as igrejas se organizem do modo que entenderem adequado, desde que não haja violação à ordem pública ou a direito de terceiros. O que a Constituição da República proíbe é que o Estado organize ou estabeleça cultos religiosos, templos ou igrejas, subvencione-os, lhes embarace o funcionamento ou mantenha com eles ou seus representantes, relações de dependência ou aliança (Fachin, 2015).

Nesse diapasão, tomando o didático fracionamento utilizado por Sarlet (2015) em liberdade religiosa (liberdade de crença e de culto) e liberdade de consciência, ressalta o autor possuírem forte vínculo. Embora próximas, não se confundem e apresentam dimensões autônomas. Sarlet defende que a liberdade de consciência assume dimensão mais ampla, se consideradas as hipóteses de objeção de consciência, que não possuem relação direta com opções religiosas.

De forma mais detalhada, Sarlet conceitua liberdade de consciência e liberdade religiosa da seguinte maneira:

Considerada em separado, a liberdade de consciência pode ser definida, com Jayme Weingartner Neto, como a faculdade individual de autodeterminação no que diz com os padrões éticos e existenciais das condutas próprias e alheias e a total liberdade de autopercepção em nível racional ou mítico-simbólico, ao passo que a liberdade religiosa (ou de religião) engloba no seu núcleo essencial tanto a liberdade de ter, quanto a de não ter ou deixar de ter uma religião, desdobrando-se em diversas outras posições fundamentais (SARLET, 2015). 
De igual forma, Mendes e Branco (2015, p. 312-320) destacam a proximidade das liberdades de consciência e de religião e adverte confusão entre elas. Ao diferenciá-las, os autores afirmam que a liberdade de consciência "tem ver a faculdade de o indivíduo formular juízos e ideias sobre si mesmo e sobre o meio externo que o circunda", não podendo o Estado interferir nessa esfera íntima. Ainda sobre o conteúdo da liberdade de consciência afirmam:

Se o Estado reconhece a inviolabilidade da liberdade de consciência deve admitir, igualmente, que o indivíduo aja de acordo com as suas convicções. Haverá casos, porém, em que o Estado impõe conduta ao indivíduo que desafia o sistema de vida que as suas convicções construíram. Cogita- se, então, da possibilidade de reconhecer efeitos a uma objeção de consciência.

O caso proposto para análise, sem dúvida, diz respeito à liberdade de pensamento ou consciência, uma vez que a liberdade religiosa propriamente dita refere-se, nas visões de Sarlet (2015) e Silva (2015), a desdobramentos ou dimensões da liberdade de crença e de culto. Uma vez identificado o exato direito fundamental questionado, qual seja, a liberdade de pensamento ou consciência de cunho religioso, bem como identificado seus reflexos nas relações entre particulares, insta discorrer ainda sobre as hipóteses de objeção de consciência.

\subsection{Objeção de Consciência}

Se a liberdade de consciência é reconhecida como inviolável pelo Estado, deve ele admitir que o indivíduo aja conforme suas convicções, protegendo-o quanto a suas escolhas, inclusive nas relações desenvolvidas com outros particulares. E é este o argumento de Jack Philips, proprietário da confeitaria Masterpiece Cakeshop, para se recusar a confeitar o bolo de casamento para o casal de pessoas do mesmo sexo.

Tal escusa estaria protegida pela garantia constitucional que todo indivíduo tem de não ser privado de seus direitos por motivo de crença religiosa (art. 5, VIII, CF/1988). Conforme lenciona Silva (2015, p. 242), a objeção de consciência consiste no direito de se recusar prestar determinadas imposições que contrariem as convicções religiosas ou filosóficas do interessado.

Mendes e Branco, sustentam que para que a recusa em realizar uma conduta seja considerada legítima e amparada pelo direito fundamental à liberdade de crença religiosa, ela deve estar seriamente arraigada no indivíduo, de tal sorte que a conduta prendida contradiga 
algo irrenunciável para ele, e, caso o indivíduo atendesse ao comando normativo, sofreria grave tormento moral, capaz de gerar insuportável violência psicológica. (2015, p. 313-314).

Mendes e Branco ainda pontuam dizendo que:

\begin{abstract}
A objeção de consciência admitida pelo Estado traduz forma máxima de respeito à intimidade e à consciência do indivíduo. O Estado abre mão do princípio de que a maioria democrática impõe as normas para todos, em troca de não sacrificar a integridade íntima do indivíduo. Há de se estabelecer, entretanto, uma fina sintonia entre o direito do Estado de impor as suas normas e o direito do indivíduo de viver de acordo com a pauta de valores por ele acolhida, em face da liberdade de consciência (MENDES; BRANCO, 2015, p.314).
\end{abstract}

Logo, a objeção de consciência consiste em direito constitucional de se recusar a prática de ato a todos imposta, devendo ser a escusa justificada pelo grave e insuportável sofrimento psicológico que causaria, se realizada. O ponto controvertido está justamente no fato de que, no caso sob análise, a garantia do direito de liberdade de crença e religião implicará no reconhecimento da possibilidade de adoção de um tratamento diferenciado.

O que se deve estabelecer é se este tratamento diferenciado, consistente na recusa em confeitar um bolo de casamento para um casal homossexual, será considerado um tratamento lícito ou ilícito, ou seja, determinar se o particular, no exercício de sua autonomia privada e de sua liberdade de crença e religião poderá invocar sua crença religiosa como justificativa para não adotar determinada conduta, ou se tal prática é discriminatória.

De forma clara e objetiva, Leonardo Martins explicita que somente pessoas físicas podem ser titulares do direito à liberdade de consciência. No entanto, pessoas jurídicas apenas poderão exercer tal direito se a essência da liberdade de consciência não for incompatível com o caráter artificial da pessoa jurídica (2012, p.359).

Na mesma linha, Sarlet afirma serem titulares da liberdade religiosa as pessoas físicas, e, por contemplar tal direito uma dimensão institucional, deve ser exercido, naquilo que for compatível, com o direito das pessoas jurídicas, "ainda que as pessoas jurídicas não sejam titulares, por exemplo, do direito de professar, ou não, uma religião” (2015, p. 513).

No artigo intitulado "Algumas notas sobre a liberdade religiosa na constituição federal de 1988", Sarlet, de forma mais detalhada, ao fracionar o direito ora debatido em liberdade religiosa (de crença e de culto) e liberdade de consciência, destaca, com propriedade, que tanto 
a liberdade de consciência, quanto a religiosa, podem ter como titulares pessoas físicas e jurídicas. Porém, a pessoa jurídica não faz jus à liberdade de consciência, mas somente à liberdade religiosa e, ainda assim, não quanto a todos os seus aspectos (SARLET, 2015).

\subsection{Direito Fundamental à Igualdade}

No caso em análise, o casal David Mullins e Charlie Craig registrou denúncia junto à Comissão de Direitos Civis do Colorado, alegando a prática de ato discriminatório em decorrência de sua orientação sexual, e violação, por conseguinte, do direito à igualdade. No Brasil, o direito fundamental à igualdade está previsto no artigo $5^{\circ 7}$, caput, da Constituição da República de 1988, sendo reforçado e reiterado por diversas outras normas constitucionais e infraconstitucionais.

Silva (2015, p. 211-212) sustenta que a igualdade constitui o signo fundamental da democracia. Reforça a importância do direito a igualdade ao citar o artigo $3^{\circ}$, incisos III e IV, da Constituição da República, que preceitua a igualdade como um dos objetivos da República Federativa do Brasil, repulsando veementemente qualquer forma de discriminação. Destaca a preocupação do constituinte em promover a igualdade matéria e a justiça social, sendo este objetivo das ordens econômicas e social (arts. 170, 193, 196 e 205).

A Constituição da República veda de forma expressa distinções de qualquer natureza, sendo a discriminação à orientação sexual, dentre outras, proibida, com base no inciso IV, de seu artigo $3^{\circ}$. O dispositivo constitucional preceitua como um dos objetivos fundamentais da República "promover o bem de todos, sem preconceitos de origem, raça, sexo, cor, idade e quaisquer outras formas de discriminação", reafirmando o princípio da igualdade na ordem jurídica a brasileira.

O casal David Mullins e Charlie Craig pleiteia tratamento igualitário para que seja atendido tal como os demais clientes da confeitaria, sem discriminação por causa da orientação

\footnotetext{
${ }^{7}$ Art. $5^{\circ}$ Todos são iguais perante a lei, sem distinção de qualquer natureza, garantindo-se aos brasileiros e aos estrangeiros residentes no País a inviolabilidade do direito à vida, à liberdade, à igualdade, à segurança e à propriedade, nos termos seguintes: I - homens e mulheres são iguais (...) (BRASIL, 1988).

${ }^{8}$ Art. $3^{\circ}$ Constituem objetivos fundamentais da República Federativa do Brasil: (...) III - erradicar a pobreza e a marginalização e reduzir as desigualdades sociais e regionais; IV - promover o bem de todos, sem preconceitos de origem, raça, sexo, cor, idade e quaisquer outras formas de discriminação (BRASIL, 1988).
} 
sexual. No caso a relação jurídica existente entre a confeitaria e eles caracteriza-se inquestionavelmente como uma relação de consumo, marcada pela existência de uma oferta pública de bens e serviços ao publico em geral.

Consoante esclarece Fabrício Bolzan (2015, p. 38), o tratamento diferenciado conferido às relações consumeristas é realizado pelo próprio texto constitucional, que parte do pressuposto de ser uma relação jurídica caracterizada pela desigualdade entre consumidor e fornecedor. Nessa esteira, erguem-se, ao lado do princípio da igualdade, preceitos constitucionais relacionados à ordem econômica e à defesa do consumidor.

Tal como a igualdade, consagra o artigo $5^{\circ}$ da Constituição da República, em seu inciso $\mathrm{XXXII}^{9}$, ser direito fundamental a defesa do consumidor, a qual será promovida por lei infraconstitucional (Código de Defesa do Consumidor). Com o mesmo propósito, o legislador constituinte inseriu a defesa do consumidor no capítulo da ordem econômica ${ }^{10}$ como princípio norteador daquelas relações.

Sendo a defesa e a proteção do consumidor um valor norteador da ordem econômica e das relações de consumo, ao regulamentar a defesa do consumidor, o legislador ordinário vedou de forma expressa, no artigo 39, incisos II e IX, do Código de Defesa do Consumidor, a discriminação ilícita na relação de consumo em que o fornecedor recusar o atendimento às demandas dos consumidores. Bruno Miragem (2017), ao tratar da discriminação ilícita no direito do consumidor, destaca:

Regras do CDC como as que proíbem a recusa de atendimento às demandas dos
consumidores (artigo 39, II) ou recusar a venda de bens ou a prestação de serviços,
diretamente a quem se disponha a adquiri-los mediante pronto pagamento (artigo 39 ,
IX), conduzem à ideia de uma obrigação de contratar que lhe retira qualquer
discricionariedade para a escolha de quais consumidores serão atendidos. A recusa da
contratação, assim, para que não se caracterize como discriminação ilícita, deverá ser
suportada por critério lógico e juridicamente admitido para diferenciação (exemplo:
não se concede crédito àquele que não oferece garantias), a ser reproduzido sem
distinção a todos os consumidores que se encontrem na mesma condição. Falar-se,

\footnotetext{
${ }^{9}$ Art. $5^{\circ}$ Todos são iguais perante a lei, sem distinção de qualquer natureza, garantindo-se aos brasileiros e aos estrangeiros residentes no País a inviolabilidade do direito à vida, à liberdade, à igualdade, à segurança e à propriedade, nos termos seguintes: (...) XXXII - o Estado promoverá, na forma da lei, a defesa do consumidor (BRASIL, 1988).

${ }^{10}$ Art. 170. A ordem econômica, fundada na valorização do trabalho humano e na livre iniciativa, tem por fim assegurar a todos existência digna, conforme os ditames da justiça social, observados os seguintes princípios: (...) V - defesa do consumidor (BRASIL, 1988).
}

Rev. de Direitos Fundamentais nas Relações do Trabalho, Sociais e Empresariais | e-ISSN: 2525-9903 | Maranhão | v. 3 | n. 2 | 
por outro lado, em critério que seja "juridicamente admitido", naturalmente excluirá a possibilidade que se utilize como critério de diferenciação, alguma distinção que ofenda direitos fundamentais do consumidor.

Para Walter Claudius Rothenburg (2008, p.81), o princípio da igualdade implica na proibição de discriminações indevidas. Conforme expõe o autor, a Constituição da República “tem claras disposições no sentido da vedação de discriminação, realçando a função repressiva do Direito, como instrumento social dos mais importantes para combater a discriminação odiosa". A igualdade significa evitar discriminações injustificáveis, proibindo-se o tratamento desigual de quem esteja numa mesma situação.

Em igual sentido, Rizzatto Nunes afirma que só se justifica o tratamento diferenciado em relações de consumo quando o consumidor protegido merecer tratamento favorável (2015, p. 74). Dessa forma, no que toca ao caso concreto, a diferenciação realizada pela confeitaria não se justifica, pois consumidores heterossexuais não merecem tratamento mais favorável que os consumidores homossexuais. Admitir tal diferenciação entre consumidores é promover discriminação ilícita.

\section{Restrições aos Direitos Fundamentais}

Não há discussão quanto ao fato de serem os direitos fundamentais relativos. No próprio texto constitucional, é fácil identificar que tais direitos estão sujeitos a restrições. As controvérsias surgem com relação a questões referentes ao conteúdo, ao alcance e aos limites das restrições, surgindo daí a necessidade de uma sistematização, para que se possam reduzir as controvérsias sobre o tema, como bem afirma Edilsom Farias (2000, p. 67-82). Consoante Robert Alexy (2015, p. 53-58), a restrição de um direito fundamental consiste em uma limitação do âmbito de proteção ou do pressuposto de fato desse direito. No mesmo sentido, Vinícius Diniz Vizzotto, ao tratar da restrição de direitos fundamentais, afirma:

Neste diapasão, a restrição a um direito fundamental é, em verdade, uma limitação do âmbito de proteção ou pressuposto de fato desse direito. Esse estabelecimento de limites para o exercício de certo direito fundamental é motivado pela existência, no respectivo ordenamento jurídico, de outros valores e circunstâncias em jogo. Há, assim, cidadãos detentores de direitos e inclusive interesses comunitários que devem ser sopesados para que possa dado direito fundamental ser usufruído por um indivíduo e, algumas vezes, restringido (VIZZOTTO, 2006). 
Seguindo os mesmos critérios de Canotilho (2003, p. 450), Farias afirma que uma sistematização das restrições aos direitos fundamentais, a partir da Constituição da República, comporta classificação em restrições diretamente constitucionais, restrições indiretamente constitucionais e restrições constitucionais tácitas (2000, p. 67-82).

As restrições diretamente constitucionais, são aquelas estabelecidas no próprio texto constitucional, ou seja, onde se consagra o direito fundamental, encontra-se também estatuída a restrição ao mesmo direito garantido. Paloma Braga Araújo de Souza afirma que essas restrições são facilmente identificáveis quando posicionadas em cláusula de exceção contida no próprio dispositivo que assegura o direito. Destaca ainda que as restrições diretamente constitucionais podem estar dispostas em qualquer parte do texto (2016). No que tange ao direito de liberdade de expressão religiosa (art. $5^{\circ}$, VIII), no próprio dispositivo que o consagra, existe restrição ao seu exercício, qual seja, pode o cidadão expressar suas convicções religiosas, filosóficas e morais, desde que não as use sob o pretexto de eximir-se de obrigação legal.

As restrições indiretamente constitucionais, também são denominadas de reserva de lei restritiva simples e qualificada. Tais restrições decorrem de norma infraconstitucional, mas previstas na Constituição. Dessa forma, o texto constitucional assegura o direito fundamental e, indiretamente, o restringe, ao permitir que a legislação futura poderá estabelecer a restrição. A reserva legal em questão pode se dar por meio de lei restritiva simples, ou por lei restritiva qualificada $^{11}$. Importante ressaltar que nem toda reserva de lei, ou seja, autorização constitucional para elaboração de lei atinente aos direitos fundamentais, significa uma restrição.

Em vários casos, em vez de limitar o âmbito de proteção de um direito fundamental (restrição), o que a lei faz é determinar ou regulamentar, com mais precisão, o âmbito de proteção desse direito fundamental (FARIAS, 2000, p. 67-82). A Constituição da República, apesar de no artigo $5^{\circ}$, inciso VI, garantir a inviolabilidade da liberdade de consciência e de

\footnotetext{
${ }^{11}$ Conforme Vizzotto a reserva de lei restritiva simples ocorre quando a Constituição não determina ou especifica requisitos para a elaboração da lei. A norma constitucional simplesmente autoriza a restrição, ficando a cargo do legislador estabelecer os fatores e determinações que irão configurar a limitação. No que tange a reserva de lei qualificada, afirma que essa surge quando a Constituição fixa requisitos objetivos para a lei restritiva e, dessa forma, limita a discricionariedade do legislador ordinário para estabelecer a restrição ao direito fundamental (VIZZOTTO, 2006).
} 
crença, afirma que a proteção aos locais de culto e a suas liturgias será regrada por lei qualificada. Tal imposição limita a discricionariedade do legislador ordinário para estabelecer a restrição ao direito fundamental apenas quanto à proteção aos locais de culto e às suas liturgias.

As restrições tácitas constitucionais, ou restrições não expressamente/implicitamente autorizadas pela Constituição, são aquelas que não decorrem imediatamente do texto constitucional e tampouco de reserva de lei. "São extraídas da pré-compreensão de que não existem direitos absolutos ou ilimitados. Os limites ao seu exercício decorrem da própria ordem jurídico-constitucional” (SOUZA, 2016). Farias admite que a autorização tácita constitucional dada tanto ao Poder Legislativo, como ao Poder Judiciário, de impor restrições aos direitos fundamentais, com o escopo de resolver ou evitar colisão entre direitos fundamentais, ou o conflito destes com valores constitucionalmente protegidos.

Segundo o autor, o texto constitucional não obsta que o Congresso Nacional elabore lei que acabe por restringir os direitos colidentes em determinadas circunstâncias, e, de igual forma, o Poder Judiciário não está impedido de restringir quaisquer dos direitos colidentes através das técnicas da concordância prática ou ponderação de valores no exame do caso concreto (FARIAS, 2000, p. 67-82). Nesse sentido, Sarlet (2015, 513-514), ao tratar dos limites e das restrições relacionadas à liberdade religiosa e à liberdade de consciência, ressalta que, embora sua forte conexão com a dignidade da pessoa humana, notadamente naquilo em que se externa mediante atos que afetam terceiros, são limitados e sujeitos a algum tipo de restrição, como os demais direitos fundamentais.

Sarlet, ao tratar especificadamente da liberdade de consciência, afirma que:

Modalidade que é da liberdade de expressão (manifestação do pensamento) e
especialmente da liberdade de consciência (que é mais ampla), a liberdade religiosa,
embora como tal não submetida a expressa reserva legal (no art. 5.o, VI, a CF
estabelece ser inviolável a liberdade de consciência e de crença, sendo assegurado o
livre exercício dos cultos religiosos), encontra limites em outros direitos fundamentais
e na dignidade da pessoa humana, o que implica, em caso de conflito, cuidadosa
ponderação e atenção, entre outros aspectos, aos critérios da proporcionalidade
(SARLET, 2015, 369-370).

Sarlet ainda destaca serem múltiplos os conflitos da liberdade religiosa com outros direitos fundamentais, podendo assim ser justificadas, a depender do caso, restrições quanto ao 
uso dessa liberdade (como ocorre artigo $5^{\circ}$, inciso VIII, do próprio texto constitucional), especialmente quando com isso se estiver incorrendo em prática de crime ou afetando direitos de terceiros ou interesse coletivo (SARLET, 2015, 369-370). De fato, o exercício de um direito fundamental não pode implicar em lesão a direito fundamental alheio, nem contrariar a ordem pública.

\section{Colisão entre Direitos Fundamentais}

A colisão entre direitos fundamentais, de maneira geral, ocorre quando o exercício de um direito fundamental, por parte do seu titular, colide com o exercício do direito fundamental, por parte de outro titular. No caso Masterpiece Cakeshop v. Colorado Civil Rights Commission, o direito à liberdade de consciência religiosa garantiria ao proprietário da confeitaria, Jack Philips, a possibilidade de recusar-se a confeitar e a vender um bolo para comemorar a união de duas pessoas do mesmo sexo, algo contrário à sua convicção religiosa. Contrapõe-se a essa liberdade de consciência religiosa o direito de Charlie Craig e David Mullins de serem tratados de igual forma que os demais consumidores, proibindo-se expressamente atos discriminatórios em razão da origem, raça, sexo, cor, idade e quaisquer outras formas de discriminação.

Conforme explicita Leandro Sousa Bessa (2006), diante de uma situação de dúvida quanto à aplicabilidade de direitos fundamentais em aparente conflito, ou seja, de qual dos direitos fundamentais deverá prevalecer sobre o outro, o primeiro passo rumo à solução é a fixação do âmbito de proteção do direito fundamental, ou seja, identificar a parcela da realidade que o constituinte houve por bem definir como objeto da proteção daquela garantia fundamental.

Para o autor, há situações que, à primeira vista (interpretação literal), podem ludibriar o intérprete, de forma que surge a necessidade de se precisar o âmbito de proteção de cada direito fundamental. Cita o autor diversas correntes que procuram alcançar tal desiderato. Entretanto, destaca haver casos em que o âmbito de proteção é mais facilmente delineável, tal como ocorre quando este é instituído direta e expressamente pelo próprio ordenamento jurídico. Nessa última hipótese, assim descreve:

Rev. de Direitos Fundamentais nas Relações do Trabalho, Sociais e Empresariais | e-ISSN: 2525-9903 | Maranhão | v. 3 | n. 2 | p. 131 - 153 | Jul/Dez. 2017. 
É o chamado âmbito de proteção estritamente normativo. Ao legislador cabe definir o próprio conteúdo do direito regulado. Estes direitos, ao mesmo tempo em que têm sua concretização e conformação dependentes da atuação do legislador, delegam a este a tarefa de vincular e obrigar o Estado (...). Importante se faz o estudo do âmbito de proteção dos direitos fundamentais porque, muitas vezes, determinadas situações, que à primeira vista caracterizariam um conflito de direitos fundamentais, não o são verdadeiramente. $\mathrm{O}$ que se observa no caso é uma simples mensuração incorreta do âmbito de proteção. É a chamada colisão aparente. De fato, a colisão não ocorre, mas uma simples aparência de conflito de normas veiculadoras de direitos fundamentais, sanável pela fixação dos âmbitos de proteção de ambos, a fim de que não mais se interpenetrem.

Diferentemente é o que ocorre nos casos em que há a autêntica colisão entre direitos fundamentais, a qual persiste mesmo após a verificação dos respectivos âmbitos de proteção, exigindo do interprete a observância de outros processos para a solução do conflito, tal como o sopesamento dos interesses envolvidos, as circunstâncias fáticas e jurídicas, a partir da análise das especificidades e peculiaridades do caso concreto.

\section{Direito à Igualdade nas relações em que há oferta de bens e serviços ao público.}

Aquele que oferece bens e serviços ao público em geral sinaliza sua predisposição a contratar com todo aquele que aceite as condições contratuais previamente estabelecidas, razão pela qual, apresenta-se contraditório e incongruente que, após realizada a oferta pública de bens e serviços este se negue a celebrar o contrato em razão do sexo, idade, religião, orientação sexual ou qualquer outra característica pessoal do pretenso contratante.

Ao assim agir, recusando-se a celebrar contrato com aquele que aceita as condições da oferta realizada, o ofertante de bens ou serviços ao público em geral prática discriminação ilícita. A emissão de declaração da vontade de contratar deve vir acompanhada de todas as condicionantes exigidas pelo ofertante, desde que não sejam odiosas, suspeitas ou abusivas, tais como raça ou orientação sexual, e sejam indispensáveis a promoção de um objetivo razoável e legítimo do proprietário aberto ao público.

Nas relações jurídicas de natureza consumerista, em que há oferta de bens e serviços ao público, há que se destacar que o ordenamento jurídico não pode pretender que os particulares confiram tratamentos estritamente igualitários, uma vez que é da própria essência das relações 
jurídicas privadas a liberdade de estipulação do conteúdo contratual, de modo que é natural que cada contrato contenha conteúdo específico, objeto de negociação entre os particulares.

O que não se admite é que aquele que fez a oferta pública se recuse a cumprir seus termos e condições, em razão de características do pretenso contratante, salvo se elas tiverem sido excepcionadas na própria proposta e desde que não atentatórias contra a dignidade da pessoa, tais como aquelas relacionadas à raça, etnia, orientação sexual, orientação religiosa, as quais dificilmente serão toleradas e consideradas lícitas, uma vez que não amparadas pela realização de objetivos constitucionalmente legítimos.

A recusa em contratar baseada orientação sexual dificilmente estará amparada pela liberdade de contratar ou pela autonomia privada, haja vista que, nestes casos, a recusa em contratar e a não admissão da pessoa no estabelecimento aberto ao público, além de dificilmente se sustentar em motivo ou objetivo legítimo, importará em inquestionável tratamento vexatório e degradante, violador da dignidade da pessoa discriminada. ${ }^{12}$

Alfaro Aguila-Real destaca que nestes casos o particular abusa de seu direito de liberdade de contratação, ao submeter o outro particular, em razão da negativa de contratação, a tratamento humilhante e, portanto, contrário a sua dignidade e ao ordenamento jurídico. Nestas situações, a recusa em contratar não é ilícita apenas por ser discriminatória, mas pelo fato de violar a dignidade do outro contratante, ${ }^{13}$ pensamento compartilhado por Vieira de Andrade, que aponta a necessidade de se proibir apenas as discriminações que afetem de forma intolerável a dignidade humana. ${ }^{14}$

Conforme destaca Alfaro Aguila-Real, ao tratar da necessidade de combate às práticas discriminatórias:

\footnotetext{
${ }^{12}$ Em igual sentido destaca Bilbao Ubillos que: "Es evidente que cuando la negativa a prestar un servicio obedece a motivos raciales, la exclusión constituye una afrenta vejatoria, un agravio para todos los integrantes del colectivo discriminado, que hiere en lo más profundo seu orgullo y su dignidade." (BILBAO UBILLOS, 2006, p.165)

${ }_{13}$ "Lo que sucede es que el riesgo de tratamento vejatorio al que hemos aludido se actualiza especialmente en relación con la negativa de contratar discriminatória (...) por la especial conexión que el derecho a la igualdad tiene con la dignidad humana, pero esto no significa que una negativa de contratar sea ilícita por ser discriminatória" (ALFARO AGUILA-REAL, 1993, p. 114)

${ }^{14}$ VIEIRA DE ANDRADE, 2009, p. 295.
} 
Os estabelecimentos abertos ao público, administrados por particulares, não podem considerar-se espaços estritamente privados. Dessa maneira, quem abre um local ao público afirma de alguma maneira a sua vontade de contratar com qualquer pessoa que aceite os preços e condições de venda. Provavelmente não pode dizer-se que existe uma obrigação de contratar, mas deve se ter em conta que a abertura de um local implica, de certo modo a renúncia em selecionar cada cliente. Estaríamos diante de uma atuação que excede os limites da autonomia de contratar (ALFARO AGUILAREAL, 1993, p. 78-79).

A grande dificuldade em se admitir a possibilidade de que um estabelecimento aberto ao público, no exercício de sua liberdade da contratação, não contrate em razão de características pessoais decorre do fato de que ao atuar no mercado o estabelecimento manifesta e torna pública a sua vontade de contratar, razão pela qual, qualquer pessoa que deseje contratar nas condições previamente fixadas poderá fazê-lo. ${ }^{15}$

Conforme destaca Aguilera Rull "o decisivo será agora o círculo de destinatários ao qual o oferente dirige a sua declaração de vontade. Se dirigir-se a um círculo indeterminado de pessoas deverá garantir-lhes o acesso em igualdade de condições, sem poder excluir certas pessoas por sua orientação sexual."16 Para Bilbao Ubillos:

Não há que se olvidar que quem explora este tipo de estabelecimento (cafeterias, restaurantes, hotéis e etc) dirigem sua oferta ao público em geral, manifestam a sua vontade de contratar, em principio, com qualquer que aceite seus preços e condições de venda. Ainda que não exista propriamente uma obrigação de contratar, a abertura do local implica, ao menos, na renúncia de selecionar com critérios individuais a sua clientela. Outra coisa são as condições que se podem impor com caráter geral e que tem um fundamento objetivo e razoável, como a advertência formulada em cartazes colocados na entrada (BILBAO UBILLOS, 2007, p.165).

\footnotetext{
${ }^{15}$ No âmbito do ordenamento jurídico brasileiro, inexistem instrumentos normativos específicos destinados a normatizar a aplicabilidade do princípio da igualdade nas relações jurídicas privadas. A despeito disso, há que se destacar, dada relevância e pertinência temática que, configurada a natureza consumerista da relação jurídica, nos termos do inciso IX, do artigo 39, do Código de Defesa do Consumidor, constitui prática abusiva a recusa de venda de bens ou a prestação de serviços, diretamente a quem se disponha a adquiri-los mediante pronto pagamento.

${ }^{16}$ Conforme original, "lo decisivo será ahora el círculo de destinatários al que el eferente dirige sua declaración de voluntad. Se dirigirse a un círculo indeterminado de personas deberá garantizarles a todas ellas el aceso en igualdad de condiciones, sin poder excluir a ciertas personas por sua origen racial o sexo" (AGUILERA RULL, 2009, p.16). Em igual sentido, destaca Cerdá Martinez-Pujalte que: "detrás de todo subyace el pensamento de que aquellos que ponen sus mercancias y servicios a disposición del público tienen el deber de desenvolverse de forma neutral em dicho mercado. La oferta hecha se dirige a cualquiera y es independiente de si la parte oferente actúa en el mercado de forma habitual com uma inteción empresarial o no." (CERDÁ MARTINEZ-PUJALTE, 2009, p.117) Conforme destaca Vazques de Castro: "La forma en que se ponga en conocimiento del publico no tiene sin embargo importância, así como el número de personas que a través de ese medio realmente tengan conocimiento de la oferta. No presentan problemas los casos en que se utilicen los medios de comunicación pública - radio, prensa, $t v$, internet -, a través de los cuales se ven informados un número indeterminado e indeterminable de personas." (VAZQUEZ DE CASTRO, 2010, p. 108)
} 
Aquele que oferece bens e serviços ao público em geral sinaliza sua predisposição a contratar com todos aqueles aceitem as condições contratuais previamente estabelecidas, renunciando o direito de selecionar seus contratantes com base em critérios individuais. Desse modo, o direito de liberdade, seja o de contratar, seja o de crença e religião, não poderá ser utilizado como justificativa para a recusa em contratar, em especial, quando o critério para a recusa for odioso e não encontrar qualquer objetivo legítimo ou razoável.

\section{Considerações Finais}

O caso Masterpiece Cakeshop v. Colorado Civil Rights Commission tem como pano de fundo o conflito entre dois princípios constitucionais, quais sejam, o direito fundamental à liberdade de consciência religiosa e o direito fundamental à igualdade. Em outras palavras, o caso envolve o direito de alguém recusar a agir de forma contrária às suas convicções religiosas e o direito de alguém exigir tratamento igualitário.

Certamente, uma das questões mais polêmicas na atualidade é definir o grau de eficácia do princípio da igualdade nas relações entre particulares e seus efeitos sobre a autonomia privada e a liberdade de contratação. A questão se torna ainda mais controvertida quando para além da liberdade de contratar, aquele que recusa a contratar com outrem aduz suas convicções religiosas como motivo para a não contratação.

De fato, aquele que oferece bens e serviços ao público em geral sinaliza sua predisposição a contratar com todo aquele que aceite as condições contratuais previamente estabelecidas, renunciando a possibilidade de escolher o contratante com base em características individuais, razão pela qual, apresenta-se contraditório e incongruente que, após realizada a oferta pública de bens e serviços este se negue a celebrar o contrato em razão do sexo, idade, religião, orientação sexual ou qualquer outra características pessoal.

Ao se analisar a eficácia do princípio da igualdade nas relações jurídicas envolvendo estabelecimentos abertos aos públicos, verifica-se que a recusa em contratar com pessoas em razão de suas características pessoais tende a ser inadmitida, uma vez que, em regra, expõe 
aquele que não foi admitido a um tratamento publico vexatório, principalmente se a recusa se basear na raça, origem étnica ou orientação sexual da pessoa discriminada, critério tendencialmente considerados odiosos e ilícitos.

Quando há oferta realizada ao público, o ofertante acaba por renunciar ao direito de selecionar os contratantes sob bases individuais, de modo que a recusa, nessas circunstâncias, evidência uma conduta discriminatória, um ato de desprezo pela pessoa inadmitida. Ao atuar no mercado, ofertando seus bens e serviços, o proprietário do estabelecimento manifesta e torna pública a sua vontade de contratar, razão pela qual, qualquer pessoa que deseje contratar nas condições previamente fixadas poderá fazê-lo.

Desse modo, o direito de liberdade, seja o de contratar, seja o de crença e religião, não poderá ser utilizado como justificativa para a recusa em contratar, em especial, quando o critério para a recusa for odioso e não encontrar qualquer objetivo legítimo ou razoável. O Código de Defesa do Consumidor, em consonância com o texto constitucional, proíbe o tratamento discriminatório, não sendo lícita a diferenciação entre consumidores homossexuais e consumidores heterossexuais.

O presente trabalho, portanto, sem a pretensão de esgotar um tema tão polêmico e relevante, teve por desiderato contribuir para o debate acerca do conflito entre o direito de liberdade de crença e religião e o direito ao tratamento igualitário, a partir da análise do caso Masterpiece Cakeshop v. Colorado Civil Rights Commission, cujo julgamento certamente representará um marco para a temática da eficácia do direito à igualdade nas relações entre particulares e os limites ao exercício da escusa de consciência religiosa.

\section{REFERÊNCIAS}

ALEXY, Robert. Teoria dos Direitos Fundamentais. Tradução de Virgílio Afonso da Silva. $2^{\circ}$ ed. São Paulo: Malheiros, 2011. 669 p.

AGUILERA RULL, Ariadna. Proibición de discriminación y libertad de contratación. Barcelona: Faculdad de Derecho de la Universidad Pompeu Fabra. Revista para el analisis del Derecho, 2009, p.1-30.

AGUILERA RULL, Ariadna. El proyecto de lei integral para la igualdad de trato y la no discriminación. Barcelona: Faculdad de Derecho de la Universidad Pompeu Fabra. Revista para el analisis del Derecho, 2011, p.1-15. 
AGUILERA RULL, Ariadna. Contratación y diferencia: Prohibiciones de discriminación por sexo y origen étnico en el acceso a bienes y servicios disponibles al público. Universitat Pompeu Fabra. Barcelona, 2010.

ALFARO AGUILA-REAL, Jesús. Autonomia privada y derechos fundamentales. Anuario de Derecho Civil, 1993, p. 57-122.

ADAM LIPTAK (New York). The New York Times. Justices to Hear Case on Religious Objections to Same-Sex Marriage. The New York Times. New York, 26 jul. 2017.

BERNARDES, Cláudio Márcio; PEDROSA, Márcio Eduardo Senra Nogueira. O ensino domiciliar como expressão da liberdade religiosa no estado democrático de direito. Universitas Jus, Brasília, v. 27, n. 3, 2017, p.145-155.

BESSA, Leandro Sousa. Colisões de Direitos Fundamentais: propostas de Solução. In: Congresso Nacional do CONPEDI, 2006, Fortaleza. Anais do XIV Congresso Nacional do CONPEDI. Florianópolis: Fundação Boiteux, 2006. p. 301-302. Disponível em: <http://www.publicadireito.com.br/conpedi/manaus/arquivos/anais/XIVCongresso/125.pdf >. Acesso em: 05 ago. 2017.

BILBAO UBILLOS, Juan Maria. Los derechos fundamentales em la frontera entre lo público y lo privado: la noción de state action en la jurisprudencia norteamericana. Madri: McGraw-Hill. 1997.

BILBAO UBILLOS, Juan Maria. La eficácia de los derechos fundamentales frente a particulares. Madrid: Centro de Estúdios Políticos y Constitucionales, 1997.

BOLZAN, Fabrício. Direito do Consumidor Esquematizado. $3^{\text {a }}$ ed. São Paulo: Saraiva, 2015. $735 \mathrm{p}$.

CANOTILHO, J.J. Gomes. Direito Constitucional e Teoria da Constituição. 7. ed. Coimbra: Almedina, 2003.

CERDÁ MARTINEZ-PUJALTE, Carmen. El problema de la discriminación en el ámbito privado: una aproximación a las legislaciones recientes en Alemania y España. Universidad Externado de Colombia. Revista de Derecho Privado, n. ${ }^{\circ}$ 16, 2009, p. 103-146.

FACHIN, Zulmar. Curso de direito constitucional. $7^{\text {a }}$ ed. rev. e atual. Rio de Janeiro: Forense, 2015.

FARIAS, Edilsom. Restrição de direitos fundamentais. Sequiência: Estudos Jurídicos e Políticos, Florianópolis, p. 67-82, jan. 2000. Disponível em: <https://periodicos.ufsc.br/index.php/sequencia/article/view/15416/13989>. Acesso em: 03 ago. 2017.

Rev. de Direitos Fundamentais nas Relações do Trabalho, Sociais e Empresariais | e-ISSN: 2525-9903 | Maranhão | v. 3 | n. 2 | p. 131 - 153 | Jul/Dez. 2017. 
MARTINS, Leonardo. Liberdade e Estado Constitucional: leitura jurídico-dogmática de uma complexa relação a partir da teoria liberal dos direitos fundamentais. São Paulo: Atlas, 2012. $405 \mathrm{p}$.

MORAIS, Márcio Eduardo Pedrosa. Religião e direitos fundamentais: o princípio da liberdade religiosa no estado constitucional democrático brasileiro. Revista Brasileira de Direito Constitucional - Rbdc: Revista do Programa de Pós-Graduação "Lato Sensu" em Direito Constitucional, São Paulo, v. 18, p.225-242, jul. 2011. Semestral. Disponível em: Disponível em: <http://www.esdc.com.br/RBDC/RBDC-18/RBDC-18-225-

Artigo_Marcio_Eduardo_Pedrosa_Morais_(Religiao_e_Direitos_Fundamentais_o_Principio_ da_Liberdade_Religiosa).pdf $>$. Acesso em: 27 jul. 2017

MENDES, Gilmar Ferreira; BRANCO, Paulo Gustavo Gonet. Curso de Direito Constitucional. 10a ed. São Paulo: Saraiva, 2015. 1470 p.

MIRAGEM, Bruno. Discriminação no consumo vai além dos ingressos para mulheres em festas. Revista Consultor Jurídico, São Paulo, SP, jul. 2017. Disponível em: $<$ http://www.conjur.com.br/2017-jul-05/garantias-consumo-discriminacao-consumo-alemingressos-mulheres-festas>. Acesso em: 30 jul. 2017.

NUNES, Rizzatto. Curso de Direito do Consumidor. $10^{\text {a }}$ ed. rev. e atual. São Paulo: Saraiva, 2015. 936 p.

ROTHENBURG, Walter Claudius. Igualdade material e discriminação positiva: o princípio da isonomia. Revista Novos Estudos Jurídicos, Itajaí, SC, v. 13, n. 2, p.77-92, dez. 2008. Semestral. Disponível em: <https://siaiap32.univali.br/seer/index.php/nej/article/view/1441〉. Acesso em: 30 jul. 2017.

SARLET, Ingo Wolfgang. ALGUMAS NOTAS SOBRE A LIBERDADE RELIGIOSA NA CONSTITUIÇÃO FEDERAL DE 1988. Doutrinas Essenciais de Direito Constitucional, São Paulo, v. 8, p.829-845, ago. 2015.

SARLET, Ingo; MARINONI, Luiz Guilherme; MITIDIERO, Daniel. Curso de Direito Constitucional. $4^{\mathrm{a}}$ ed. ampl. São Paulo: Saraiva, 2015. 1432 p.

SILVA, José Afonso da. Curso de Direito Constitucional Positivo. 26ª ed. rev. e atual. São Paulo: Ed. Malheiros, 2005. 924 p.

SOUZA, Paloma Braga Araújo de. Restrições aos direitos fundamentais. In: Âmbito Jurídico, Rio Grande, XIX, n. 149, jun. 2016. Disponível em: <http://ambitojuridico.com.br/site/?n_link=revista_artigos_leitura\&artigo_id=17377>. Acesso em: 05 ago. 2017.

STEVE KURTZ (New York). Fox News Channel. Supreme Court tackles gay rights: Why Masterpiece Cakeshop case could rival Hobby Lobby decision. 2017. 
VAZQUEZ DE CASTRO, Luis Martinez. El princípio de libre desarrollo de la personalidade en el ámbito privado. Pamplona: Civitas, 2010.

VIERA DE ANDRADE, José Carlos. Os direitos fundamentais na Constituição portuguesa de 1976. $3^{\text {a }}$ ed. Coimbra: Almedina, 2009.

VIZZOTTO, Vinicius Diniz. Restrição de direitos fundamentais e segurança pública: uma análise penal-constitucional. Revista Jus Navigandi, Teresina, PI, ano 11, nº 1116, jul. 2006. 